\title{
"A proposed model for applying total quality management in Syrian banks: a case study in the industrial bank of Syria"
}

\begin{tabular}{|c|c|}
\hline AUTHORS & $\begin{array}{l}\text { Ali Salman } \\
\text { Ing. Samuel Mintah } \\
\text { Tomáa Hes } \\
\text { Ing. Haiyan Sulaiman }\end{array}$ \\
\hline ARTICLE INFO & $\begin{array}{l}\text { Ali Salman, Ing. Samuel Mintah, Tomáa Hes and Ing. Haiyan Sulaiman (2016). A } \\
\text { proposed model for applying total quality management in Syrian banks: a case } \\
\text { study in the industrial bank of Syria. Investment Management and Financial } \\
\text { Innovations, } 13(2-1), 149-156 \text {. doi:10.21511/imfi.13(2-1).2016.03 }\end{array}$ \\
\hline DOI & http://dx.doi.org/10.21511/imfi.13(2-1).2016.03 \\
\hline RELEASED ON & Monday, 04 July 2016 \\
\hline JOURNAL & "Investment Management and Financial Innovations" \\
\hline FOUNDER & LLC "Consulting Publishing Company "Business Perspectives" \\
\hline
\end{tabular}

NUMBER OF REFERENCES

0

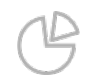

NUMBER OF FIGURES

0

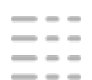

NUMBER OF TABLES

0

(C) The author(s) 2022. This publication is an open access article. 
Ali Salman (Syrian Arabic Republic), Ing. Samuel Mintah (Czech Republic), Tomáš Hes (Czech Republic), Ing. Haiyan Sulaiman (Czech Republic)

\title{
A proposed model for applying total quality management in Syrian banks: a case study in the industrial bank of Syria
}

\begin{abstract}
Syrian banks have witnessed an important change since 2002 with applying the advanced technology. Industrial bank played a crucial role in developing the industrial sector which provides about $25 \%$ to the GDP and this sector is the main engine of the national economy in Syria. This research aims to apply total quality management (TQM) to industrial banks of Syria. A random sample of 120 bank employees from higher and middle management were selected to investigate the current situation of TQM in the bank and to develop a new suitable TQM Model. The results show the levels of implementing TQM criteria in the industrial bank, and provide a proposed TQM Model with an implementation plan that could help other Syrian banks to apply TQM in an effective way.
\end{abstract}

Keywords: total quality management, industrial bank, industrial sector, Syria.

JEL Classification: L15, L16, G21.

\section{Introduction}

Quality management is important to achieve success in every organization. Total quality management (TQM) which can be termed as a management approach and culture of managing an organization (Shahin and Dabestani, 2011) has gained the attention of the world over the past few years as one management strategy that can harness the successful performance of many organizations. TQM is a philosophy of organizational management with an emphasis on mutual cooperation which involves stuffs at every level of the organizational structure with the aim of achieving improvement in all aspect of the organization (Al-Shobaki et al., 2010).

Practitioners as well as researchers have both embraced the idea of TQM and have proven the significant impact that practice has on overall performance and effectiveness of firms. As noted by Prajogo and Sohal (2003), TQM has played a bigger role on the growth of management practices on the practical and theoretical fronts and as such many industries, especially in most developed economies, embracing the idea of total quality management.

Due to changes in the global economy coupled with market forces, the drive for improved quality, productivity and competition in the world market has been the top priority of many organizations (Hunt, 1992). The need for total quality management strategies was, however, inevitable and, therefore, the evolution of the concept of total quality management

(C) Ali Salman, Ing. Samuel Mintah, Tomáš Hes, Ing. Haiyan Sulaiman, 2016.

Ali Salman, Faculty of Economics, Program in Quality Management Syrian Virtual University, Damascus, Syrian Arabic Republic.

Ing. Samuel Mintah, Faculty of Tropical AgriSciences, Czech University of Life Sciences Prague, Czech Republic.

Tomáš Hes, Ph.D., Faculty of Tropical AgriSciences, Czech University of Life Sciences Prague, Czech Republic.

Ing. Haiyan Sulaiman, Ph.D. Student, Faculty of Tropical AgriSciences, Czech University of Life Sciences Prague, Czech Republic.
(Beyo-Moriones and Merino-Diaz, 2001). Sohal and Terziovski (2000) state that over the last decade, TQM has been a major business strategy practiced by most leading manufacturing industries in the world and as such TQM does not only strive for customer satisfaction through the provision of services and products that meets customer needs but also continues provision of such services in an improved way (Sohal and Terzivski, 2000).

The finance industry of Syria with a critical view shows a deteriorating of quality in service and product provision to customers of the industry. TQM practice is, therefore, necessary for all banks in Syria. This is important due to the imminent challenge posed by the threat of their existence and continuity in the labor market such as the high competition in the global market, the rapid technological development and the global economic openness. Quality is one of the competitive priorities that all modern managers seek for and, hence, it's a requirement for all administrative management in banks to change the traditional administrative method and to look for modern management methods. Therefore the adoption of the TQM concepts and it principles in an effective way ensures that banks can meet these challenges and achieve competitive advantage required in the labor market.

The deterioration and challenges faced by the finance industry call all Syrian banks to search for solutions or new administrative philosophy that helps to mitigate these obstacles. The adoption of Syrian banks to the concept of total quality management and work on the application in these challenges and the steady deterioration of the quality of services ensure positive results such as: meeting the needs and wants of customers, increasing customer satisfaction as well as continuance and completion. 
The adoption of total quality management is an important competitive weapon that can be used by banks to attract customers, achieve excellence and to become leaders in the banking market. TQM is a management concept that has been established on a set of ideas and important guiding principles so that any banks management can implement it to achieve a positive organization culture to motivate development in order to achieve customer satisfaction and increase competitiveness.

\section{Literature review}

Most literature notes the origination of the TQM innovation as far back as the early 1920s. Stuelpnagel (1993) states that the origination of the concept started in 1926 by referring to Crowter's book entitled "My Life and Work". However, known authors such as Feigenbaum, Ishikawa, Deming, Juran and Crosby are known as the founders of the term. The term was very popular in Japan after World War II when the country needed industrial transformation. Deming (1982) introduced new quality control concepts which were adopted by many American manufacturers after the First World War. They began to utilize basic quality concepts coupled with other management techniques for improved employee motivation and business measurement process (Weis, 2001).

TQM is believed to have emerged as a replacement for total quality control (TQC) which was coined by Feigenbaum (1961). TQC was an effective system proposed for provision of economical products and services for customer satisfaction by integrating the quality development, quality improvement and quality maintenance at all levels of an organization (Ehigie and McAndrew, 2005). However, the concept of TQC did not include management ideologies such as teamwork, development of supplier relationships and people empowerment which are incorporated into the new total quality management concept. The combination use of quality management and philosophies of management was referred to as total quality management (Al-Amri, 2012).

There is still no concrete definition of total quality management. Oakland (1991) defines the term as a way of striving to achieve improved effectiveness and flexibility of businesses. It involves a means whereby each level of an organization is involved in the management process (Oakland, 1990). Lakhe and Mohanty (1994) also define TQM as "a continuous quest for excellence by creating the right skills and attitudes in people to make prevention of defects possible and totally satisfy customers/users at all times". Findings of many studies provide evidence of the positive impact of TQM programs implementing. Wali and Boujelbene (2011) showed that organizations that have implemented the use of
TQM had improved performance at various levels of the organization (Wali and Boujelbene, 2010).

The banking industry is often noted as the largest industry that deals with the needs of the population. Through the daily interaction between customers and banking service providers, the provision of high quality services is significant in the banking industry (Angur et al., 1999). Most often banks maintain long-term relationships with their customers and, therefore, quality service provision is important for the industry. As one of the largest sectors of any economy, the banking sector reflects almost all critical features of perceived customer service quality which is essential for achieving excellence in growth of the industry. Many authors such as Ahmed and Hassan (2003) have suggested the need for research into TQM implementation in the financial or banking sectors to investigate the performance of banks and, as well, propose the best practices that will improve not only the financial performance of the industry but also maintenance of quality in service provision and continual customer satisfaction.

This study would, therefore, contribute to the existing knowledge on TQM implementation on the financial sector of Syria by: (1) identifying the current leadership in the industrial bank of Syria and it's compatibility with TQM; (2) evaluating the current strategy in the industrial bank of Syria and its compatibility with TQM requirements; (3) identifying the current people management in the industrial bank of Syria and it's compatibility with TQM requirements; (4) identifying the current operations management in the industrial bank of Syria and it's compatibility with TQM requirements; (5) evaluating the current information system in the industrial bank of Syria and its compatibility with TQM portal; (6) evaluating the current customer focus in the industrial bank of Syria and its compatibility with TQM requirements; (7) evaluating the current development and continued improvement in the industrial bank of Syria and its compatibility with TQM requirements; (8) developing a model used to apply TQM in the bank under study and compare with the current performance of the bank, and contribute to improving banking performance level and the quality of services of the banks under study; (9) identifying the necessary criteria for implementing TQM in industrial bank of Syria; (10) identifying the specific requirement criteria of the proposed model for applying TQM in the bank under study; (11) identifying the application impediments of the proposed model, and; (12) developing a plan for applying the proposed model of TQM in the industrial bank of Syria. 


\section{Materials and method}

Based on the study nature, a questionnaire was employed as the mode of data collection. A survey was conducted in the industrial bank of Syria from August 1st to September 7th, 2015, to investigate the current situation of TQM in the industrial bank of Syria and to develop a new suitable TQM model. A random sample of bank employees from higher and middle management was selected and then they were asked to complete the questionnaires. Data was collected from these questionnaires, of which, 92 of the 120 administered were completed. The data was then processed and validated before being transferred to the SPSS software (version 22). Finally, the data was then statistically analyzed.

2.1. Model specification. In order to answer the objectives of the study, a simple regression model was chosen. The base line model is given below.

$Y^{*} i t=\beta_{0}+\sum_{i=1}+\beta_{i} X_{t i}+\varepsilon_{t i}$,

where: $\mathrm{Yit}^{*}=$ dependent variable (total quality management in industrial bank) $X=$ independent variables (leadership, strategy, people management, operation management, customer focus, information system, continual improvement), $i=$ banking institution, $t=$ time, $\beta_{0}=\mathrm{a}$ constant, $\beta_{1}=$ regression coefficients to be estimated.

\section{Results}

The first part of the analysis is the test of reliability, followed by the descriptive statistics and finally the inferential statistics. All data analysis was carried out using the SPSS software (version 22.).

3.1. Test for reliability and validity. The reliability of scale of variables was estimated by calculating the Cronbach's Alpha. The variables were put to the scale reliability test, and the Cronbach's Alpha $(\alpha)$ value obtained was $0.97(n=92)$, this shows the high reliability levels of the scales used for the recording the scores of variables given by the respondents from the employees at the industrial bank of Syria.

3.2. Descriptive statistics. Table 1 shows the mean and the standard deviation of the independent and dependent variables and it can be seen. The means range for independent variables was from 2.4928 to 2.7808. The standard deviations range for independent variables was from 0.84429 to 0.92526 . The mean of dependent variable was 2.6470 while the standard deviation was 0.78205 . These values show that the TQM in industrial bank is applied at the weak level.

3.3. Inferential statistics. Table 2 presents the sample T-test of independent variables at a test value equal to 3 and confidence interval of the difference equal to $95 \%$, and it will be noticed that the significance values of T-test is less than significance value of the study at $p(0.05)$, this shows that there are significant differences between independent variables (leadership, strategy, people management, operation management, customers focus, information system, continual improvement) and the dependent variable (TQM in bank).

Table 3 shows the Pearson correlations coefficients values between the independent variables (leadership, strategy, people management, operation management, customers focus, information system, and continual improvement) and the dependent variable (TQM in bank). This was used in this test to show if there is any relation between the independent variables and the dependent variable. From Table 3, we can deduce that significance value of the Person correlations coefficients for all variables was equal to 0 and it's less than the significance value at $p(0.05)$. The Pearson correlation values range was equal from 0.858 to 0.920. It shows a positive significant relation between the independent variables and the dependent variable (TQM) within the bank.

Table 4 shows the simple regression analysis between the independent variables (leadership, strategy, propel management, operation management, customers focus, information system, and continual improvement) and the dependent variable (TQM in bank), it was used to show if there was any effect on the dependent variable from the independent variables. It can be seen from the Table 4 that, the range of R-Square value was 0.737 to 0.847 which implies that about $74 \%-85 \%$ of the variables was explained by the model and, therefore, could be deemed fit for the study. Also, the Significance value of ANOVA for all variables was equal to 0 and it's less than the significance level at $\mathrm{p}(0.05)$. The significance values range of T-test for all variables was equal to 0 and 0.003 and it is less than the significance value of the study was equal to 0.05 . As a result, it's found that there is a strong positive effect from the independent variables on the dependent variable.

3.4. The proposed TQM model. The foundations used to build the proposed model are dependent on the results of the study. The proposed model is a working plan aimed to help Syrian banks under study to transfer the concepts and principles of TQM to working practices, as shown in Figure. The proposed model is a framework based on integration of several criteria in order to support the main criteria which is the customers focus. The performance system of the proposed model consists of 7 criteria: leadership, strategy, continual improvement, customers focus, people management, 
operating management, and information system. Looking at Figure 1, it can be seen that the proposed model is centred on the integration of criteria of leadership, strategy, and continual improvement and people management, operating management, information system, to support the most important criteria of the model represent with costumers focus. It is most important as it's the main focus of total quality management operation. While the arrows represent the importance of feedback and exchange of information, they also show the importance of learning, innovation, creativity and knowledge in order to improve the process of customers focus and, thus, achieve sustainability and profitability of the bank under study.

3.5. Implementation of the proposed model. The researcher sets up an implementation plan aimed to correct the criteria in the bank under study by applying some requirements that help in implementing the proposed model. It was divided into three phases.

\subsubsection{Leadership and strategy correction. From the} analysis in the study, the result showed that the mean of the leadership was equal to 2.731 and the range means of items that used to scale the leadership criteria are between 2.282-2.902. This phase is aimed to correct the leadership of the bank under study to that of a leadership more suitable and positive to the TQM concept and it principles so that the test value of the study can be achieved. Here the study proposes the following: (a) choosing leaders who have the efficiencies and qualifications and the training appropriate; (b) involve all the respective personnel in the bank management through delegation of authority and teamwork in addition to finding the supported organizational structures, and; (c) leaders must stimulate the employees and appreciation their efforts and praise them either physically or mentally to develop their qualifications, skills and expertise. This, in turn, is expected to yield increase relationship between leaders with employees, flexible relationships between different administrative levels and an increase in employee satisfaction and loyalty.

Also, the result of the study showed that the mean of the strategy was equal to 2.78 and the range means of items that used to scale the strategy criteria are between (2.64-2.94). This phase is aimed to correct the strategy of the bank under study to that of a strategy more suitable and positive to the TQM concept and its principles so that the test value of the study can be achieved. This phase aimed to correct the strategy of the bank under study to a strategy more suitable and positive to the TQM by applying the following requirements: (a) strategy should fit the external environment and every respective personnel in the bank; (b) strategy should be available to every respective personnel in the bank, and; (c) organizational structure suits and supports the strategy. After successful implementation, we expect a continuity of the good performance and quality in all modes and various events of the organization.

3.5.2. Customer focus correction. As can be deduced from the study results, the mean of the costumers focus was equal to 2.602 and the range means of items that used to scale the costumers focus criteria are between 2.282-2.902. This phase is aimed to correct the costumers focus of the bank under study to that of a costumers focus more suitable and positive to the TQM concepts and it principles so that the test value of the study can be achieved. In order to achieve this correction, the organization must ensure full assimilation of needs and expectations of customers. More so, the delivery of the needs and expectations of customers to all levels in the bank must be ensured with following the appropriate actions to increase customer satisfaction. Achieving this would, therefore, enhance an increase in the number of bank customers, increase in market share and an increase in customer satisfaction about the services and operations provided.

3.5.3. Operational and people management correction. Another aspect of organizational management is the management of people as well as the operations of the organization. From the study results, the mean of the people management was equal to 2.549 and the range means of items that used to scale the people management criteria are between 2.1732.880 and that of operation management was equal to 2.647 and the range means of items that used to scale the operation management criteria are between 2.1523.097. This phase aims to find a correction to both people management and operation management to ensure quality service provision by the banks under study. By providing appropriate measures to ensure policies of equality and equal opportunities for workers in the bank, creating an institutional culture that deepens team spirit and mutual cooperation in bank, evaluation of the performance of employees consistently by the banks management and continuous training to improve the performance of employees, we expect an improvement in people management. Under taking the above mentioned strategy will ensure an increase in the loyalty of worker and increase in the expertize and skills of workers as it shows by the reports performance as well.

On the side of operational management, we propose that, the banks under study should identify and develop processes based on the specific needs of the bank. Also they must ensure employees absorb to their roles and responsibilities, provide indicators to measure the performance of operation and follow-up operation performance constantly in order to enhance and development. It is, therefore, expected that after 
successful implementation this would yield a low rate of errors and deviations in operations, ease and speed of operations implementation and improve efficiency of existing operations provided by bank.

\section{Discussion}

Fulfilling the preconditions of expectations of this analysis, conclusions of this research are based upon adequate data sample as shown by the results of the Cronbach's Alpha test showing a high reliability of the test method used in relation to the scores of variables. The inferential statistics on the other hand, provided an insight in the deep differences of values of T-tests using the sample T-test of independent variables, such as the leadership, strategy, people management, operation management, customers focus, information system and continuous improvement, which comes at a surprise, while confirming these as significant, and corroborating the dependent and not incidental character of the variables. This result also speaks of a need for cautious consideration of different variables, within the banking management system, as these can show strong disparities in their values and should be therefore considered as individual, independent classes on the top of being a cluster of strongly interrelated phenomenon. Furthermore, there is a positive significant relation between the independent variables and the dependent variable (TQM) within the bank, as shown by the Pearson correlation coefficient, which was further confirmed by the intensity of this relationship, as per the R-Square coming from the simple regression analysis, depicting a strong impact of the independent variables on the dependent variable and leading to confirmation of a strong positive effect of the independent variables on the TQM.

Although the study does not provide exhaustive answers on the pillars of a successful TQM, as in such case much broader analysis would have to be undertaken, the summarizing conclusion from the results can thus be that a success of TQM strategy in the sample bank is indeed firmly grounded on the variables selected, as the individual values in these classes have a relevant impact on the functioning of TQM, highlighting the importance of operational management, leadership and of the continuous improvement between the chosen variables, being the variables with the higher explanatory impact. The efficiency of TQM finds its base in the individual qualities, as described by the independent variables, yet the differences in the values of the mentioned independent variables indicate that the landscape of each of the classes may rather less prone to be compared with the other ones, implying a need for further, more detailed study examining the impact of each of the variable on TQM in a separated exercise. The general view of the processes within a bank, being a result of this test, thus, points at a colorful, varied and rather more complex cluster of interwoven processes that may resist to a simple explanation and need to be seen in a panoramatic perspective, requiring further studies in the future on the interplay of different elements within a TQM system of a financial intermediary.

\section{Conclusion}

Total quality management in the past few years has been an indispensible ingredient for the success of many organizations. However, the Syrian banking sector in recent times is suffering from quality deterioration in terms of service provision. This study therefore sought to propose a model for the application of TQM in the banking sector of Syria. The research shows the levels of implementing TQM criteria in the industrial bank of Syria, and provides a proposed TQM Model with an implementation plan that helps the Syrian bank and specifically the Industrial Bank of Syria to apply TQM in an effective way.

\section{Acknowledgment}

This research was enabled due to financing provided by CULS IGA project reg.nr. 20165006.

\section{References}

1. Shahin, A. Dabestani, R. (2011) A feasibility study of the implementation of total quality management based on soft factor, Journal of Industrial Engineering and Management, 4(2), pp. 258-280. doi:10.3926/ jiem.2011.v4n2.p258-280.

2. Al-Shobaki, S.A., Fouad, R.H. and Al-Bashir, A. (2010) The implementation of total quality management (TQM) for the banking sector in Jordan, Jordan Journal of Mechanical and Industrial Engineering, 4(2), pp. 304-313.

3. Prajogo, D.I., Sohal, A.S. (2003). The relationship between TQM practices, quality performance, and innovation performance: an empirical examination, International Journal of Quality Reliability Management, 20(8), pp. 901-918.

4. Hunt, V.D. (1992). Quality in America: How to Implement a Competitive Quality Program. Homewood, IL: Business One Irwin.

5. Beyo-Moriones, Merino-Diaz de Cerio, J (2001). Quality management and high performance work practice: do they coexist, International Journal of Production Economics, 73(3), pp. 251-259.

6. Sohal, A.S., Terzivski, M. (2000). TQM in Australian manufacturing: factors critical to successes, International Journal of Quality and Reliability Management, 17(2), pp. 158-167.

7. Deming, W.E. (1982). Quality, Productivity, and Competitive Position. Cambridge, MA: MIT Center for Advanced Engineering Study, UK.

8. Stuelpnagel, T.R. (1993). De'ja` vu: TQM returns to Detroit and elsewhere, Quality Progress, 26(9), pp. 91-95. 
9. Weis, R.J. (2001). A Potential Solution to Provide Assurance that Total Quality Management Programs Add Long Term Value. California State University Dominguez Hills: Master Thesis.

10. Feigenbaum, A.V. (1961). Total quality control, McGraw-Hill, New York.

11. Ehigie, B.O., McAndrew, E.B. (2005). Innovation, diffusion and adoption of total quality management, Management Decision, 43(6), p. 925-940.

12. Al-Amri A.A.H. (2012). The Total Quality Management Practices in Yemeni Public Universities.

13. Oakland, J.S. (1990). "TQM-3, What Next?”, Total Quality Management: Proceedings of 3rd International Conference, IFS Ltd, Springer-Verlag, London, pp. 133-154.

14. Wali, S., Boujelbene, V. (2011). Cultural Influences on TQM Implementation and Financial Performance in Tunisian Firms.

15. Angur, M.G., Nataraajan, R., Jahera, J.S. (1999). Service quality in the banking industry: an assessment in a developing economy, International Journal of Bank Marketing, 17(3), pp. 116-123.

16. Ahmed, S., Hassan, M. (2003). Survey and case investigations on application of quality management tools and techniques in SMIs, International Journal of Quality and Reliability Management, 20(7), pp. 795-826.

\section{Appendices}

Table 1. Descriptive statistics

\begin{tabular}{|l|l|c|c|c|c|c|c|c|c|}
\hline \multicolumn{2}{|l|}{} & Leadership & Strategy & $\begin{array}{c}\text { People } \\
\text { management }\end{array}$ & $\begin{array}{c}\text { Operation } \\
\text { management }\end{array}$ & $\begin{array}{c}\text { Customers } \\
\text { focus }\end{array}$ & $\begin{array}{c}\text { Informatio } \\
\mathrm{n} \text { system }\end{array}$ & $\begin{array}{c}\text { Continual } \\
\text { improvement }\end{array}$ & $\begin{array}{c}\text { TQM in } \\
\text { Bank }\end{array}$ \\
\hline \multirow{2}{*}{$\mathrm{N}$} & Valid & 92 & 92 & 92 & 92 & 92 & 92 & 92 & 92 \\
\cline { 2 - 10 } & Missing & 0 & 0 & 0 & 0 & 0 & 0 & 0 & 0 \\
\hline Mean & 2.7319 & 2.7808 & 2.5497 & 2.6475 & 2.6025 & 2.7239 & 2.4928 & 2.6470 \\
\hline \multicolumn{2}{l}{ Std. deviation } & .92526 & .85125 & .84101 & .86921 & .86698 & .84429 & .91485 & .78205 \\
\hline
\end{tabular}

Source: processed data in SPSS V22.

Table 2. One-sample test of independent variables

\begin{tabular}{|c|c|c|c|c|c|c|}
\hline & \multicolumn{6}{|c|}{ Test value $=3$} \\
\hline & \multirow{2}{*}{$t$} & \multirow{2}{*}{$d f$} & \multirow{2}{*}{ Sig. (2-tailed) } & \multirow{2}{*}{ Mean difference } & \multicolumn{2}{|c|}{$95 \%$ confidence interval of the difference } \\
\hline & & & & & Lower & Upper \\
\hline Leadership & -2.779 & 91 & .007 & -.26812 & -.4597 & -.0765 \\
\hline Strategy & -2.470 & 91 & .015 & -.21920 & -.3955 & -.0429 \\
\hline People management & -5.136 & 91 & .000 & -.45031 & -.6245 & -.2761 \\
\hline Operation management & -3.890 & 91 & .000 & -.35248 & -.5325 & -.1725 \\
\hline Customers focus & -4.398 & 91 & .000 & -.39752 & -.5771 & -.2180 \\
\hline Information system & -3.137 & 91 & .002 & -.27609 & -.4509 & -.1012 \\
\hline Continual improvement & -5.318 & 91 & .000 & -.50725 & -.6967 & -.3178 \\
\hline
\end{tabular}

Source: processed data in SPSS V22.

Table 3. Pearson correlations coefficients values

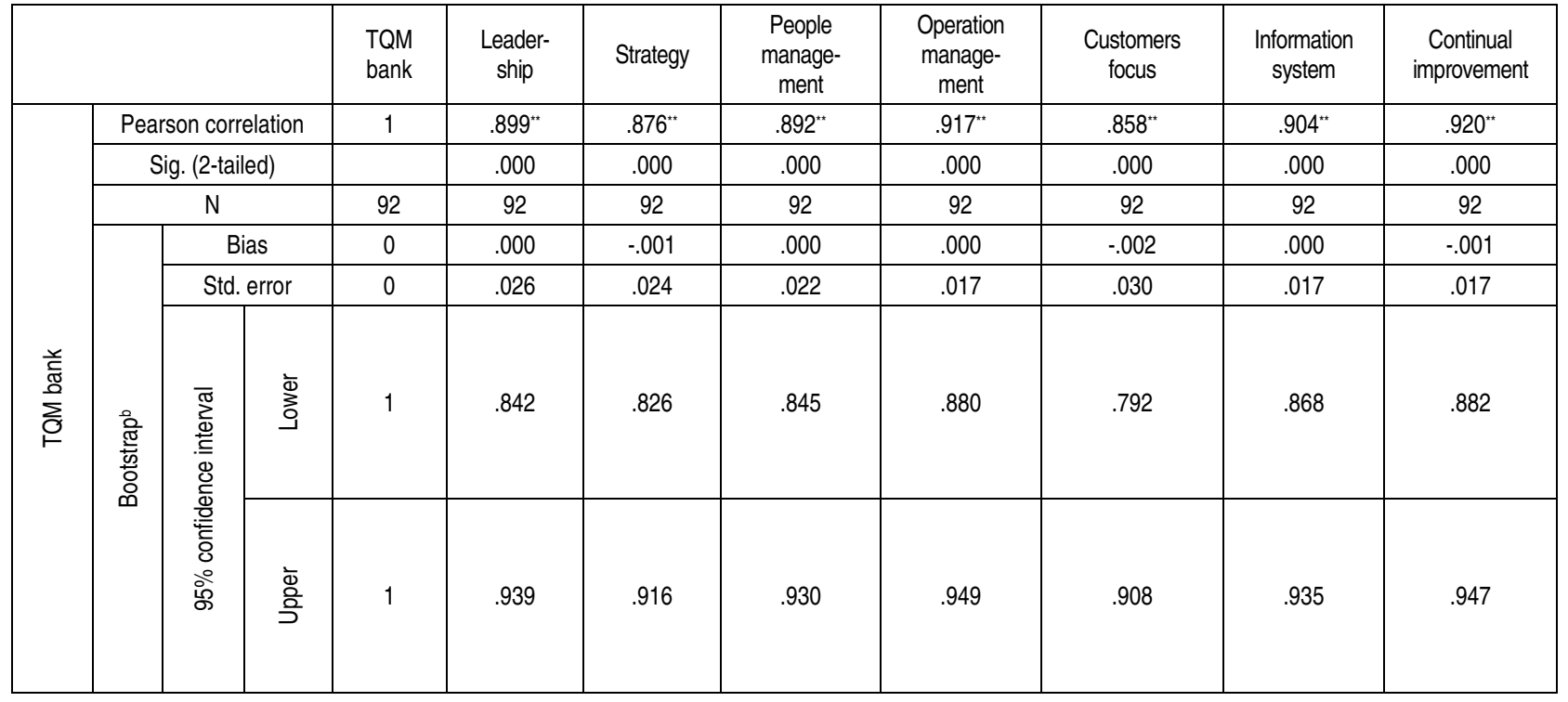

Source: processed data in SPSS V22. 
Table 4. Simple Regression Analysis Values

\begin{tabular}{|l|c|c|c|c|c|c|}
\hline \multirow{2}{*}{ Model } & Model summary & \multicolumn{2}{c|}{ ANOVA } & \multicolumn{3}{c|}{ Coefficients } \\
\cline { 2 - 7 } & $R$-square & $F$ & Sig & Beta & $t$ & Sig \\
\hline Leadership & .808 & 378.910 & .000 & .899 & 5.078 & .000 \\
\hline Strategy & .767 & 296.719 & .000 & .876 & 3.013 & .003 \\
\hline People management & .795 & 349.537 & .000 & .892 & 4.476 & .000 \\
\hline Operation management & .842 & 478.111 & .000 & .917 & 4.393 & .000 \\
\hline Customers focus & .737 & 252.159 & .000 & .858 & 4.725 & .000 \\
\hline Information system & .818 & 404.194 & .000 & .904 & 3.075 & .003 \\
\hline Continual improvement & .847 & 496.656 & .000 & .920 & 7.329 & .000 \\
\hline
\end{tabular}

Source: processed data in SPSS V22.

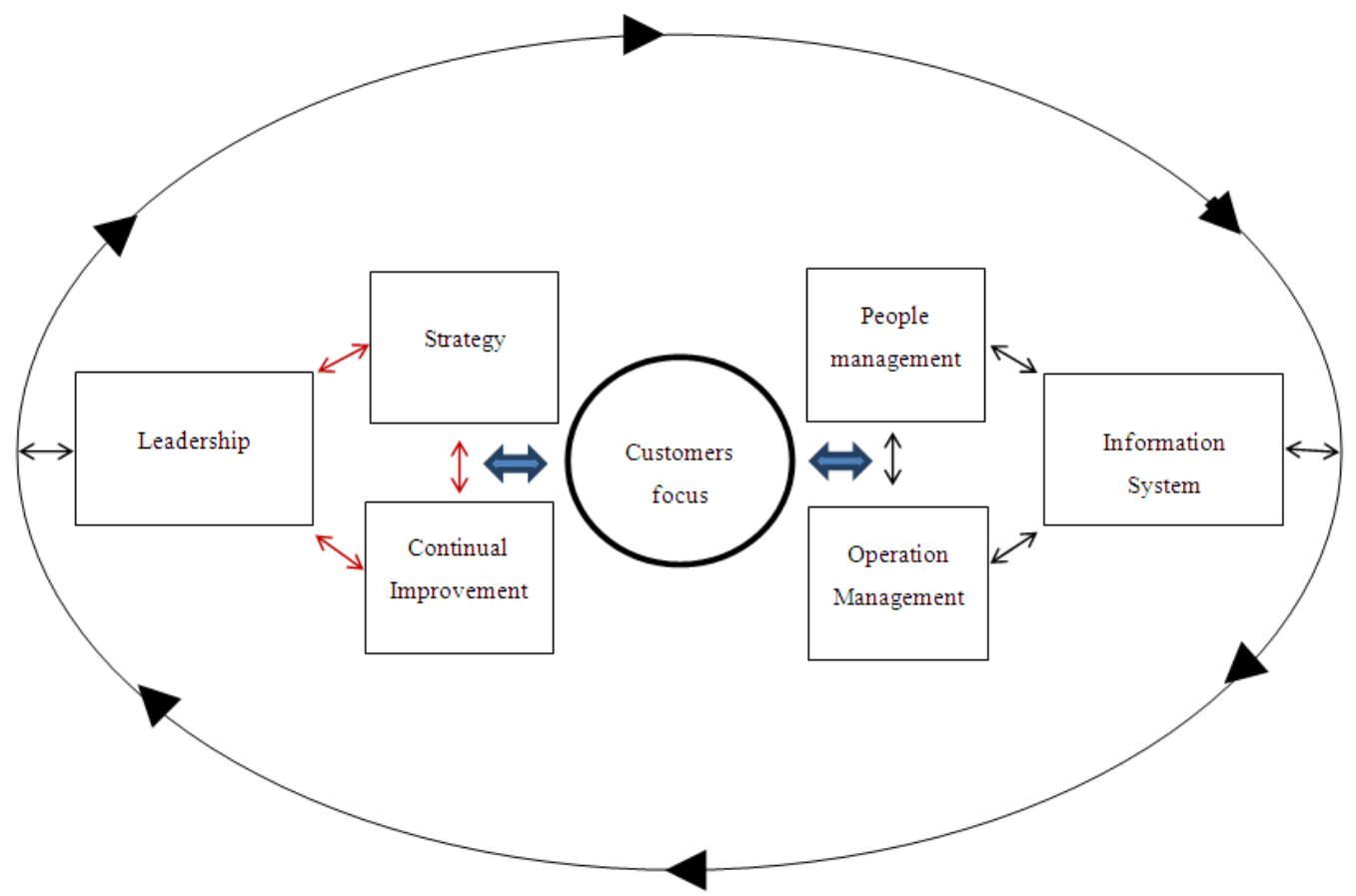

Source: authors.

Fig. 1. (Jad) proposed TQM model in bank

Questionnaire:

\begin{tabular}{|c|c|c|c|c|c|}
\hline Acceptance degree & 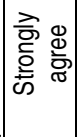 & 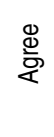 & 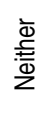 & 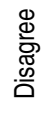 & 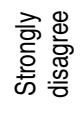 \\
\hline \multicolumn{6}{|l|}{ Leadership } \\
\hline \multicolumn{6}{|l|}{$\begin{array}{l}\text { Does your bank apply and support the culture of collective leadership to manage the bank operations and conduct of } \\
\text { its affairs? }\end{array}$} \\
\hline \multicolumn{6}{|l|}{ Does your bank management have the necessary competence and qualifications to do its business successfully? } \\
\hline \multicolumn{6}{|l|}{ Does your bank review and improve the effectiveness of personal conduct for managers? } \\
\hline \multicolumn{6}{|l|}{ Does your bank management has the transparency and responsibility about everyone concerned in bank? } \\
\hline \multicolumn{6}{|l|}{$\begin{array}{l}\text { Does your bank management has the flexibility and the ability in making the right decisions based on the available } \\
\text { information, experience and prior knowledge? }\end{array}$} \\
\hline \multicolumn{6}{|l|}{ Does the management of bank give the power to subordinates? } \\
\hline \multicolumn{6}{|l|}{ Does your bank management encourage all employees to submit ideas and suggestions innovative and creative? } \\
\hline \multicolumn{6}{|l|}{ Does the management of your bank appreciate the employees efforts and their achievements appropriately at the right time? } \\
\hline \multicolumn{6}{|l|}{ Does your bank management seeks to engage all employees in the bank and get their support and contributions? } \\
\hline \multicolumn{6}{|l|}{ Strategy } \\
\hline \multicolumn{6}{|l|}{ Does the bank strategy based on the understanding of the external environment and the customer needs? } \\
\hline \multicolumn{6}{|l|}{$\begin{array}{l}\text { Does your banks strategy based on the understanding of the internal performance of the bank and the available } \\
\text { possibilities? }\end{array}$} \\
\hline Does your bank develop rreview and update its strategy with the supporting policies? & & & & & \\
\hline
\end{tabular}


Questionnaire (cont.):

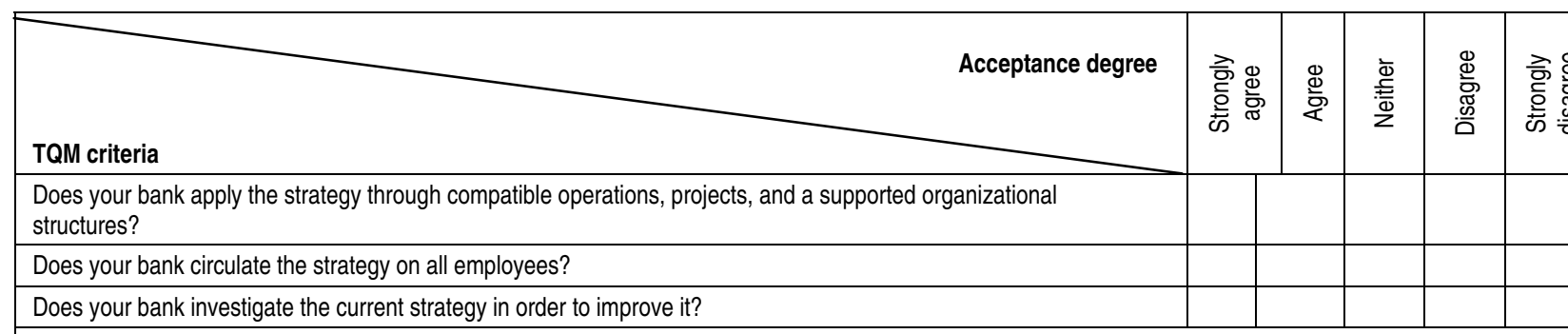

People management

Does your bank relies on suitable policies to ensure equality and equal opportunities in recruitment and promotion process and employees reward?

Does your bank determine the skills and competencies of employees and the required performance level to achieve the vision, objectives and strategy?

Does your bank seek to develop the organizational culture continuously in order to raise the effectiveness of mutual cooperation of the team spirit at all levels of the bank?

Does your bank encourage the exchange of information and knowledge process between employees?

Does your bank seek to achieve dialogue between all levels of the bank?

Does your bank motivate employees and encourage them to participate in the continuous improvement of operations

then estimate their efforts and achievements?

Does your bank evaluate the performance of employees regularly?

Does your bank provide the necessary training to improve employees performance regularly?

$$
\text { Operation management }
$$

Does bank consider its specific needs before setting up plans and operations?

Are the bank operations easy and not complex?

Are the employees know their roles and responsibilities in implementation, maintenance and development the bank operations?

Does the bank provide a measurable indicators for operations performance?

Does the bank review the efficiency and effectiveness of major operations in order to identify weaknesses and opportunities for improvement points?

Does the bank compare between its operations and other banks operations in order to enhance creativity, innovation

and improvement processes?

Does the bank provide a studies regularly for developing banking operations?

$$
\text { Customers focus }
$$

Does the bank have a diverse services and compatible with the different customer needs?

Does the bank meet customer needs around the clock?

Does the bank interested in searching for customer needs and expectations?

Does the bank deliver customer needs and expectations to all bank levels?

Does the bank manage customer relationships according to a clear and structured approach?

Does bank measure the customer satisfactions about services and operations that provided?

Does the bank follow the appropriate actions that aimed to increase customer satisfaction?

Information system

Does the bank depend on an integrated information system for all activities and bank processes?

Does the banks information system specialized in strength and durability and accessibility?

Does the bank information system specialized in quick access to the data to be obtained?

Does the bank review the efficiency and effectiveness of the available system information in order to identify weaknesses and opportunities to develop it?

Does the bank compare the available information system with applicable information system in other banks in order to identify strengths, weaknesses and work to improve it?

\section{Continual improvement}

Does the bank identify the improvements and necessary developments and works on approval them?

Does the bank set an indicative targets for improvement and continuous development process?

Does the bank put continuous improvement to services, operations and systems as an essential target for everyone in

the bank?

Does the bank provide the necessary training programs that will train workers on methods and tools of continuous improvement?

Does the bank provide the necessary measurements to track the efficiency and effectiveness of continuous improvement process?

Does the bank management work hard to offer a new services continuously? 